\title{
Quimera: The Easy Way to Simulate Foundation Fieldbus Applications
}

\begin{tabular}{|c|c|}
\hline Journal: & Computer Applications in Engineering Education \\
\hline Manuscript ID & Draft \\
\hline Wiley - Manuscript type: & Research Article \\
\hline Date Submitted by the Author: & $\mathrm{n} / \mathrm{a}$ \\
\hline Complete List of Authors: & $\begin{array}{l}\text { Viegas, Vítor; Instituto Politecnico de Setubal, Escola Superior de } \\
\text { Tecnologia de Setúbal; Instituto de Telecomunicacoes } \\
\text { Postolache, Octavian; ISCTE-Instituto Universitario de Lisboa; Instituto de } \\
\text { Telecomunicacoes } \\
\text { Girão, Pedro; IST - Universidade de Lisboa; Instituto de Telecomunicacoes } \\
\text { Pereira, José; Instituto Politecnico de Setubal, Escola Superior de } \\
\text { Tecnologia de Setúbal; Instituto de Telecomunicacoes }\end{array}$ \\
\hline Keywords: & $\begin{array}{l}\text { Foundation Fieldbus, Simulation, Computer-assisted instruction, Process } \\
\text { control }\end{array}$ \\
\hline
\end{tabular}




\title{
Quimera: The Easy Way to Simulate
}

\section{Foundation Fieldbus Applications}

\begin{abstract}
The paper presents a simulation tool that emulates the development environment of Foundation Fieldbus (FF) applications. The idea is to use the resources provided by LabVIEW - in particular its dataflow programming paradigm - to design, execute and debug FF control strategies. Function blocks are implemented as virtual instruments, data links are represented by virtual wires, and bus monitoring tools are replaced by LabVIEW debugging tools. The simulator can easily be connected to virtual (simulated) processes or to physical (real) processes. Tests were made to evaluate the capabilities of the simulator and to assess its degree of fidelity against commercial FF systems. The goal was to release an effective, easy-to-use, low-cost training tool to disseminate knowledge about process control using the FF technology.
\end{abstract}

Keywords - Foundation Fieldbus, simulation, computer-assisted instruction, process control.

\begin{abstract}
1. Introduction
The Foundation Fieldbus (FF) is a local area network targeted for process control [1-4] supported by the FieldComm Group (http://www.fieldcommgroup.org). The FF provides all the features typically associated with process fieldbuses, including power over bus, real-time communications and digital data from the primary transducer up to the supervision room, all added to a substantial reduction of cabling costs.
\end{abstract}


The main drawback of FF systems is that, in general, they are complex and hard to configure and debug. The learning curve of FF systems is quite slow as it requires good background in areas as diverse as instrumentation, process control, communication networks and computer programming. The training process is expensive because it requires expert trainers and lastgeneration technology, preferably in real operating industrial plants, which is almost impossible for safety and economic reasons. Even bypassing the need for a real plant, designing and mounting a small pilot plant, targeted for training purposes only, is expensive, time-consuming and little flexible as it limits the range of experiments that can be done.

In this context, the use of training simulators is extremely valuable [5-9]. With these tools, trainees can simulate process dynamics, train device configuration, tune control loops, try startup, stop and shut-down sequences, and test safety mechanisms. Simulation is less expensive because it eliminates the need for real equipment, and is more flexible because it allows the programming of new training scenarios. Simulators require little maintenance, do not pose problems in terms of safety, and can be accessed anywhere provided they are web-enabled.

This paper presents a training simulator that emulates the FF application layer. The proposed solution allows the design, execution and debug of control strategies, including the possibility of interacting with the field through DAQ (Data AcQuisition) boards. The goal is to release a lowcost education tool that might be used in industrial training programs as well as in academic courses. The simulator was named Quimera (ki'mera), the Portuguese word for chimera, an illusion of the reality.

The development of FF simulators is not new. Some well-known companies provide commercial solutions, usually integrated in larger software packages, as is the case of SimulationView from Smar [10], MiMiC Simulation Software from Mynah [11], and SoftFF 
Once again, the Quimera simulator showed good match with the reality, meaning that it can effectively simulate abnormal operating conditions.

Last but not least, it is useful to compare the cost of the Quimera simulator with that of the commercial FF system. Table 2 lists all the items included in both proposals and the total cost of each. The Quimera simulator requires only $1 / 5$ of the money, which represents a significant saving.

$<$ Table 2>

Cost comparison between the Quimera simulator and the commercial FF system (all prices are approximated values in US dollars).

\section{Conclusions}

The paper presented Quimera, a simulation tool that makes use of LabVIEW's dataflow programming paradigm to emulate the application layer of FF. The proposed solution offers a real feeling of FF (as it complies with FF specifications), is very user-friendly (as it benefits from all the resources provided by LabVIEW), provides a high degree of connectivity (as it can be connected to virtual or physical processes), and is low-cost (when compared to commercial setups).

The Quimera simulator was used to control a first order system with dead time, in parallel with a commercial FF system. The results obtained were very similar, both in normal operation conditions as well as in fail state conditions, meaning that the Quimera simulator can effectively replace commercial equipment at a much lower cost.

The authors believe that the proposed solution is a good education tool that might be used in industrial training programs as well as in academic courses to teach the principles of process 
control using FF. Moreover, the idea can be extended to include other flow-based programming environments (such as Simulink) and other block-based fieldbuses (such as Profibus-PA).

\section{References}

[1] D. Glanzer, Foundation Fieldbus Technical Overview, Fieldbus Foundation, 2003.

[2] I. Verhappen, A. Pereira, Foundation Fieldbus, $4^{\text {th }}$ ed., International Society of Automation (ISA), 2012, ISBN 978-1-937560-20-1.

[3] S. Sen, Foundation Fieldbus in Fieldbus and Networking, Process Automation, chapter 7, pp. 109-146, CRC Press, 2014, ISBN 978-1-4665-8677-2.

[4] J. Berge, Fieldbuses for Process Control: Engineering, Operation, and Maintenance, ISA, 2002, ISBN 1-55617-904-9.

[5] B. Balamuralithara, P. Woods, Virtual Laboratories in Engineering Education: The Simulation Lab and Remote Lab, Computer Applications in Engineering Education, Vol. 17, No. 1, pp. 108-118, March 2009.

[6] A. Kluge, J. Sauer, K. Schüler, D. Burkolter, Designing training for process control simulators: a review of emprirical findings and current practices, Theoretical Issues in Ergonomics Science, Vol. 10, No. 6, pp. 489-509, November 2009.

[7] T. Komulainen, T. Løvmo, Large-Scale Training Simulators for Industry and Academia, Proceedings from the 55 $5^{\text {th }}$ Conference on Simulation and Modelling, pp. 128-137, Denmark, October 2014.

[8] F. Fakir, D. Brunini, E. Godoy, Hardware in the Loop Simulation for Industrial Process Control, Emerson Process Experts, November 2014. 
[9] W. Grega, Hardware-in-the-loop simulation and its application in control education, Proceedings of the $29^{\text {th }}$ Annual Frontiers in Education Conference (FIE), Puerto Rico, November 1999.

[10] SimulationView Strategy Simulator - User's Manual, Smar, 2011.

[11] M. Berutti, Software Acceptance Testing with MiMiC Simulation Software, Mynah, 2008.

[12] M. Hoernicke, P. Weemes, H. Hanking, The fieldbus outside the field - Soft FF reduces commissioning effort by simulating Foundation Fieldbus, ABB Review, 2012.

[13] E. Mossin, R. Pantoni, D. Brandão, A fieldbus simulator for training purposes, ISA Transactions, No. 48, pp. 132-141, January 2009.

[14] Foundation Technical Specifications, Fieldbus Foundation, 1994-1998.

[15] Digital data communications for measurement and control - Fieldbus for use in industrial control systems - Part 2: Physical layer specification and service definition (International Standard IEC 61158-2), $3^{\text {rd }}$ ed., International Electrotechnical Commission (IEC), 2003.

[16] Creating New Front Panel Objects with LabVIEW XControls, National Instruments, 2012.

[17] R. Larsen, Data Acquisition with LabVIEW, LabVIEW for Engineers, chapter 5, pp. 142180, Prentice Hall, 2011, ISBN 978-0-13-609429-6.

[18] Using the LabVIEW Shared Variable, National Instruments, 2012.

[19] Function Blocks Instruction Manual, Smar, 2007.

[20] K. Åström, T. Hägglund, PID Controllers: Theory, Design and Tuning, $2^{\text {nd }}$ ed., ISA, 1995, ISBN 1-55617-516-7.

[21] V. Viegas, J. Pereira, Foundation Fieldbus: From Theory To Practice, International Journal of Computing, Vol. 12, No. 2, pp. 115-124, June 2013. 
[22] B. Mehta, Y Reddy, Applying FOUNDATION Fieldbus, ISA, 2016, ISBN 978-1-941546-71-0. 